\title{
Discriminating between intra- and extracellular metals using chemical extractions: an update on the case of iron
}

\author{
Christel S. Hassler ${ }^{1,2 *}$ and Véronique Schoemann ${ }^{3}$ \\ ${ }^{1}$ Center for Australian Weather and Climate Research (CAWCR), a partnership between CSIRO and the Bureau of Meteorology, \\ Castray Esplanade, Hobart 7000, TAS, Australia \\ ${ }^{2}$ Wealth for Ocean National Flagship, CSIRO, Hobart, Australia \\ ${ }^{3}$ Ecologie des Systèmes Aquatiques, Université Libre de Bruxelles, Campus de la Plaine, CP 221, Boulevard du Triomphe, 1050 \\ Bruxelles, Belgium
}

\begin{abstract}
Iron influences the climate system by limiting primary productivity. It is therefore essential to accurately measure the iron fraction associated with phytoplankton in aquatic systems. A washing procedure using EDTA, being efficient for numerous trace metals, is not strong enough to remove iron adsorbed to the surface of microorganisms. Stronger washing solutions are used for iron, but these have only been assessed for a marine diatom. This study assesses the applicability of the oxalate washing procedure for both fresh- and seawater aquatic systems. We assessed iron solubilization as a result of oxalate washing in both synthetic and natural freshwater and seawater, and we tested it on several model phytoplankton and natural assemblages from Lake Champlain, the Southern Ocean, and the Derwent River estuary. We report the effects of the oxalate solution contact time, concentration, and amendment. Our study shows that 20-min washing provides an efficient measurement of the intracellular phytoplanktonic pool of iron in both freshwater and seawater. The direct amendment of oxalate in the experimental solution presents many advantages that are critical for the measurement of size-fractionated particulate iron. These include fine control of bioaccumulation termination, a significant gain in time, and homogeneity of the washing treatment.
\end{abstract}

\section{Introduction}

The fraction of total trace metal within aquatic systems that resides in organisms has been widely recognized as an

*Corresponding author: E-mail: christel.hassler@csiro.au

\section{Acknowledgments}

C. Hassler was supported by the National Science Foundation project (Chem Oce no. 0327730 of M.R. Twiss of Clarkson University, NY, USA, and R.M.L. McKay and G.S. Bullerjahn of Bowling Green State University, OH, USA); the Swiss National Science Foundation (no. PBGEA-104637); and a CSIRO postdoctoral fellowship. The Belgian Federal Science Policy Office (contract SD/CA/03A) and Belgian French Community (ARC contract no. 2/07-287) gave support to V. Schoemann. This study is also a contribution to the SOLAS international research initiative and the European Network of Excellence EUROCEANS (contract no. 511106-2).

The authors thank J. de Jong and S.J. Phipps for useful comments on this manuscript; S.M. Havens, J. O'Sullivan, and R. Watson for technical assistance; L. Clementson and I. Jameson for pigments analysis and microscopic observations; M.R. Twiss, A.R. Bowie, and T. Remenyi for water sampling; and W. Howard, A.R. Bowie, B. Griffiths, and E.C.V. Butler for giving us the opportunity to join the SAZ-SENSE voyage on board the RV Aurora Australis. indicator of trace metal bioavailability (e.g., Worms et al. 2006). The measurement of iron (Fe) associated with phytoplankton in situ is therefore critical in reporting the Fe limitation on primary productivity that is observed in some lakes (e.g., Twiss et al. 2000, Sterner et al. 2004) and in 30\% of the ocean (high nutrient low chlorophyll [HNLC] regions, e.g., Boyd et al. 2007). Iron affects the climate system through its control on both primary productivity and carbon export (e.g., Boyd et al. 2007). Given that Fe must first be transported inside the plankton to trigger biological activities (e.g., photosynthesis), feedback regulation (e.g., induction of the secretion of siderophore), and metabolism, intracellular Fe is defined as the Fe associated within the microorganisms or irreversibly associated with the transporters (e.g., Hudson and Morel 1990). Accurate measurement of the intracellular biogenic pool of Fe is required to provide the stoichiometric ratios of Fe with respect to biomass or biogenic macromolecules (expressed in $\mathrm{C}, \mathrm{N}$, or $\mathrm{P}$ ). These ratios are used in Fe biogeochemical or climate models. Washing procedures to remove (solubilize) extracellular Fe need to be set up using model phytoplankton species and natural phytoplankton communities in both fresh- and seawater. 
Iron has two redox states: Fe(III) and Fe(II). Whereas Fe(II) is highly unstable under the oxic conditions prevailing in surface waters, Fe(III) is poorly soluble. Iron is mainly bound to organic ligands that increase its solubility and residence time in surface waters (Turner and Hunter 2001, Maranger and Pullin 2003, Chen et al. 2004). The affinity constant for organic ligands is typically several orders of magnitude higher for Fe(III) than for Fe(II) (Morel and Hering 1993, Turner and Hunter 2001). Phytoplankton are known to take advantage of these properties, using highly specific uptake transport systems to access Fe (e.g., Shaked et al. 2005). Generally, diatoms are known to use a surface reductase that reduces Fe(III) that is organically bound, thus favoring the subsequent dissociation of the Fe(II) complex and Fe internalization (Shaked et al. 2005). Under Fe-deficient conditions, cyanobacteria secrete and/or recognize siderophores (Wilhelm 1995) that efficiently compete with the organically bound Fe(III) present in the surrounding water ( $\log \mathrm{K}_{\mathrm{Fe}^{\prime} \mathrm{L}} 11.5-13.9$ in HNLC seawater; Boye et al. 2001, Croot et al. 2004). This is due to a high affinity constant of siderophores for Fe(III) (e.g., $\log \mathrm{K}_{\mathrm{Fe}^{\prime} \mathrm{L}} 11.8-16.5$ for the hydroxamate siderophore desferrioxamine B in seawater; Maldonado et al. 2005). The Fe(III)-siderophore complex is then specifically recognized by surface receptors (e.g., Völker and Wolf-Gladrow 1999). Such high-affinity transport systems imply that Fe will be strongly bound to transporters; therefore strong washing agents are required to dissociate the Fe complex on the biological surface.

Despite the fact that the EDTA washing technique is effective at reporting the intracellular pool of numerous trace metals (see Hassler et al. 2004), the technique is not strong enough to remove Fe adsorbed to the surface of microorganisms (Tang and Morel 2006). To date, two different washing solutions have been reported as being successful in discriminating total particulate and intracellular Fe in seawater (Hudson and Morel 1989, Tovar-Sanchez et al. 2003): Ti-citrateEDTA (referred to as Ti-EDTA here) and oxalate-citrate-EDTA (referred to as oxalate here). Ti-EDTA is a strong washing agent (reducing and chelating) requiring only a 2-min contact time to efficiently remove extracellular biogenic, organic, and inorganic colloidal Fe (Hudson and Morel 1989; Tang and Morel 2006); however, the reagents used to prepare this solution cause significant Fe contamination (ca. 7000 nM; Tang and Morel 2006). This is problematic when assessing particulate Fe in natural waters, where dissolved Fe concentrations can be as low as $5 \mathrm{nM}$ in freshwater (e.g., Lake Superior; Sterner et al. 2004) and $<0.1 \mathrm{nM}$ in seawater (e.g., HNLC Southern Ocean; de Baar and de Jong 2001). In addition, this washing solution has to be freshly prepared, as it is stable for only $24 \mathrm{~h}$ (Hudson and Morel 1989). The oxalate washing solution relies mainly on synergistic surface chelation and light-induced dissolution processes (Sulzberger et al. 1989, Borer et al. 2005). It has the advantages of exhibiting lower Fe background contamination (500 and $17 \mathrm{nM}$ for the basic and trace metal clean solutions, respectively;
Tovar-Sanchez et al. 2003) and of being stable for 8 weeks. Recently, Tang and Morel (2006) further optimized the oxalate washing procedure; they showed that sodium citrate was not required, that Fe washing efficiency was higher at $\mathrm{pH} 7$ than at $\mathrm{pH} 8$ (as initially recommended by TovarSanchez et al. 2003), and that an increase in the contact time with the oxalate solution from 5 min (Tovar-Sanchez et al. 2003) to $10 \mathrm{~min}$ (two successive 5-min washes) was required to measure accurate intracellular $\mathrm{Fe}$ in $T$. weissfloggi compared with Ti-EDTA washing. Following a 5- to 10-min oxalate wash, no effect on cell integrity could be seen for a wide range of eukaryotic and prokaryotic plankton (TovarSanchez et al. 2003) or on the growth rate (Tovar-Sanchez et al. 2003) or membrane integrity (Tang and Morel 2006) of Thalassiossira weissflogii. To date, the use of the oxalate wash has been limited because optimal contact time with the oxalate solution has not been clearly defined, and it was tested only on a single marine diatom in seawater under chemical conditions failing to reflect natural conditions. Tang and Morel (2006) reported a significant decrease of intracellular Fe when contact time was prolonged from 10 to $20 \mathrm{~min}$. The oxalate Fe dissolution efficiency was studied only for Thalassiossira weissflogii with 84-3340 nM Fe buffered by excess EDTA (Tang and Morel 2006) or shortterm pulse exposure to high Fe concentrations, ca. 100-1000 nM range (Tovar-Sanchez et al. 2003). Because the ability to efficiently solubilize particulate/colloidal Fe will depend on Fe chemistry (e.g., colloidal forms; Sulzberger and Laubscher 1995) and also Fe biological ligands, it is essential to study dissolution efficiency for varied organisms and environments under natural conditions. This is critical for determining the extent of Fe limitation in both fresh- and seawater systems.

In this study, we assessed the washing efficiency of the oxalate solution in both synthetic and natural waters for fresh- and seawater model phytoplankton, as well as for natural assemblages. We also report the effects of oxalate concentration and contact time. Therefore, this study represents an update of Hassler et al. (2004), as well as a further optimization of the oxalate washing procedure given in Tovar-Sanchez et al. (2003) and Tang and Morel (2006). A 20-min contact time with the oxalate solution was efficient in discriminating extracellular from intracellular iron for both freshwater and marine plankton. Given that a 20-min total contact time implies a significant increase of experimental time, constraining the amount of data that can be gathered, especially during field expeditions, an alternate direct dilution of the oxalate solution (1:10 vol:vol) in the sample before the filtration was successfully used to measure intracellular iron, thus providing a significant gain of time during experimentations. This study describes a standard procedure that can be successfully used on natural (and culture) marine and freshwater plankton, representing a critical step toward the determination of the extent of Fe limitation in aquatic systems. 


\section{Materials and procedures}

Field sampling - Natural phytoplankton was collected from Lake Champlain (May 17, 2005, Missisquoi Bay, VT, USA) and Derwent River Estuary (July 8, 2008, Woodbridge Bay, TAS, AU) in a Teflon-coated Go-Flo bottle (General Oceanics). In the Southern Ocean (SO), seawater was sampled onboard the RV Aurora Australis using Niskin-1010x bottles (January 23, 2007 at $46.41^{\circ} \mathrm{S}, 140.43^{\circ} \mathrm{E}$, and $25 \mathrm{~m}$ depth). These were placed on an autonomous 1018 rosette system that has been adapted for trace metal work (General Oceanics), attached to a Kevlar cable. Samples were kept in the dark at in situ water temperature and were processed within hours after collection.

The surface water from Lake Champlain was dominated by dinophytes (76\%, $7.0 \mu \mathrm{g}$ chlorophyll $\left.a \mathrm{~L}^{-1}\right)$, chlorophytes (14\%, $\left.1.3 \mu \mathrm{g} \mathrm{Chl} a \mathrm{~L}^{-1}\right)$, and cryptophytes (10\%, $1.0 \mu \mathrm{g} \mathrm{Chl} a$ $\mathrm{L}^{-1}$ ) (M.R. Twiss, personal communication, in situ Fluoroprobe measurement). Surface water from Woodbridge Bay was dominated by diatoms (with presence of Pseudonitzschia, Nitzschia, Cerataulina, Skeletonema, and Chaetoceros) with some cryptophytes, haptophytes, and dinoflagellates (I. Jameson and L. Clementson, personal communication, microscope observation and HPLC pigment analysis, $0.5 \mu \mathrm{g} \mathrm{Chl} a \mathrm{~L}^{-1}, 29.6$ salinity). The seawater from the SO was dominated by haptophytes, diatoms, and chlorophytes (L. Clementson, personal communication, HPLC pigment analysis, $\left.0.4 \mu \mathrm{g} \mathrm{Chl} a \mathrm{~L}^{-1}\right)$.

Choice and maintenance of organisms-Cyanobacteria were chosen as model phytoplankton because they have a wide distribution $\left(70^{\circ} \mathrm{N}\right.$ to $50^{\circ} \mathrm{S}$; Veldhuis et al., 2005). Both Phaeocystis and diatoms are major phytoplankton groups that recurrently bloom in the SO (Smith and Asper 2001, Schoemann et al. 2005, Sarthou et al. 2005) and have significance for C export (DiTullio et al. 2000, Sarthou et al. 2005, Boyd et al. 2007).

The freshwater cyanobacteria, Synechococcus PCC7942 (University of Toronto), were maintained in Fraquil growth media (450 nM total Fe buffered with EDTA; Morel et al. 1975) at $19^{\circ} \mathrm{C}$ under continuous light of $50 \mu \mathrm{mol}$ quanta $\mathrm{m}^{-2} \mathrm{~s}^{-1}$, which was provided by white fluorescent tubes (see Hassler et al. 2006). The Antarctic seawater diatom Chaetoceros sp. CS-624 and the haptophyte Phaeocystis sp. CS-243 (CSIRO Microalgal culture collection) were grown in Aquil growth media (Price et al. 1988/89; with total Fe decreased to 2 nM buffered with EDTA) at $4^{\circ} \mathrm{C}$, with continuous fluorescent light of 50 and 20 umol quanta $\mathrm{m}^{-2} \mathrm{~s}^{-1}$, respectively. The Aquil growth media was slightly modified based on comparison with other artificial seawater media (Harrison et al. 1980, Berges et al. 2001), and enriched with total $\mathrm{Zn}$ (15-fold, $60 \mathrm{nM}$ ), Co (4-fold, $10 \mathrm{nM}$ ), $\mathrm{Cu}$ (1.2-fold, $1.2 \mathrm{nM}$ ), and $\mathrm{Ni}$ (at the level found in the artificial seawater, $6 \mathrm{nM}$; Berges et al. 2001) to avoid biological limitation (see Hudson and Morel 1993, Wilkinson and Buffle 2004). The selenium concentration was set to $1 \mathrm{nM}$ (10-fold decreased), similar to the level found in oceanic water. Chemical speciation calculation in the low-Fe Aquil media used
(Mineql+ v. 4.5 with updated stability constants from NIST version 8.0, ionic strength corrected by the Davies equation, calculation made at $25^{\circ} \mathrm{C}$ and $\mathrm{pH}$ 8.0) gives similar free ion concentrations from the original Aquil recipe (except for higher free $\mathrm{Zn}, \mathrm{Co}$, and $\mathrm{Cu}$ ) and 2000-fold decreased inorganic Fe (4 pM). Model phytoplankton were isolated using gentle filtration $(<5 \mathrm{mmHg})$ on a polycarbonate membrane $(0.2 \mu \mathrm{m}$ for cyanobacteria; $2 \mu \mathrm{m}$ for other species) and rinsed three times with Fraquil or Aquil without trace metals (see below) prior to resuspension in the experimental solution.

Experimental solutions and extraction of the surface bound iron-For freshwater model phytoplankton, the experimental solutions consisted of Fraquil in absence of any micronutrients except Fe (100 nM total Fe, $\mathrm{pH} 6.8)$ or $0.2 \mu \mathrm{m}$ filtered Lake Champlain water. For seawater model phytoplankton, the experimental solution was the Aquil media in absence of any micronutrients ( $\mathrm{pH} 8.0$ ) or $0.2 \mu \mathrm{m}$ filtered SO water. For model plankton, experimental media were spiked with ${ }^{55} \mathrm{Fe}$ (as $\mathrm{FeCl}_{3}$ kept in $0.5 \mathrm{M} \mathrm{HCl}$; Perkin Elmer) to reach a final specific activity of $25 \mathrm{nCi} \mathrm{mL} \mathrm{m}^{-1}$ (specific activity at the day of use, $64.22 \mathrm{mCi} \mathrm{mg}^{-1} \mathrm{Fe}$ ) for freshwater and $3.8 \mathrm{nCi} \mathrm{mL}^{-1}$ (specific activity at day of use, $67.99 \mathrm{mCi} \mathrm{mg}^{-1} \mathrm{Fe}$ ) for seawater and left to equilibrate overnight at the experimental temperature. Radioactive Fe addition resulted in $7 \mathrm{nM}$ and $1 \mathrm{nM}$ Fe enrichment for freshwater and seawater, respectively. Model plankton were then spiked to reach an abundance of $10^{5}$ cells $\mathrm{mL}^{-1}$ for freshwater species and $10^{4}$ cells $\mathrm{mL}^{-1}$ for seawater species. The natural phytoplankton (Lake Champlain, SO, Derwent River estuary) was kept in the water collected in the field, to which ${ }^{55} \mathrm{Fe}$ was added.

Experimental solutions with ${ }^{55} \mathrm{Fe}$ and phytoplankton were then incubated in 1-L polycarbonate containers for $12 \mathrm{~h}$ under continuous light $\left(50 \mu \mathrm{mol}\right.$ quanta $\left.\mathrm{m}^{-2} \mathrm{~s}^{-1}\right)$ at in situ temperature $\left(19^{\circ} \mathrm{C}\right.$ for freshwater, $12^{\circ} \mathrm{C}$ for $\mathrm{SO}, 10^{\circ} \mathrm{C}$ for Woodbridge, and $4^{\circ} \mathrm{C}$ for model marine species). The ${ }^{55} \mathrm{Fe}$ cellular content was then determined following different treatments (see below). Samples were collected by gentle filtration $(<5 \mathrm{mmHg})$ on $0.4-\mu \mathrm{m}$ polycarbonate filters for freshwater species and 0.45- $\mu \mathrm{m}$ nitrocellulose filters for seawater species.

To determine the efficiency of the oxalate to remove $\mathrm{Fe}$ bound to abiotic natural colloidal and particulate Fe, filtered water from Woodbridge Bay (0.2- $\mu \mathrm{m}$ polycarbonate filter) was spiked with $1 \mathrm{nM}{ }^{55} \mathrm{Fe}$ and left to equilibrate in the dark at ambient water temperature for $72 \mathrm{~h}$. The Fe fraction retained on a $0.2-\mu \mathrm{m}$ polycarbonate filter was then determined for oxalate and $\mathrm{NaCl}(0.6 \mathrm{M})$ treatments.

Filters were rinsed three times with nonradioactive solution (major salts of Fraquil and Aquil or 0.2- $\mu \mathrm{m}$ filtered natural water) and stored in scintillation vials with $5 \mathrm{~mL}$ scintillation cocktail (F count, Fisher Scientific, for freshwater experiments; Ultima Gold, Perkin Elmer, for seawater experiments). Iron-55 was measured using a $\beta$-counter (RKB Wallac model $1219 \operatorname{Rack} \beta$ for freshwater experiments; Tricarb Packard 2900 TR for seawater experiments) and was 
transformed into disintegrations per minute (dpm) using appropriate quenching curves. The iron-55 dpm were then used to assess the washing efficiency (\%) of the different treatments compared with three rinses with Aquil, Fraquil, or filtered natural water (i.e., 0 min contact time with the oxalate solution) (Fig. 1). Each experiment was done in triplicate. Data were represented in percent to allow direct comparison of the oxalate washing efficiency for different media and microorganisms. Using nominal enrichment resulting from the ${ }^{55} \mathrm{Fe}$ addition, the measured dissolved Fe concentrations (see below), and Chl $a$, intracellular Fe was expressed in nmol Fe $\mu \mathrm{g}$ Chl $a^{-1} \mathrm{~h}^{-1}$. For the experiment using SO water, parallel radiocarbon incubations of 50- to $100-\mathrm{mL}$ samples were conducted with a final concentration of $100 \mu \mathrm{Ci} \mathrm{L}^{-1}$ sodium ${ }^{14} \mathrm{C}$ bicarbonate (as per Schoemann et al. 2001). The results from the inorganic carbon uptake were used to calculate the Fe-to-carbon uptake ratio ( $\mu \mathrm{mol} \mathrm{Fe:mol} \mathrm{C).}$

Dissolved Fe was measured using the competitive ligand exchange adsorptive voltammetry technique (CLE-AdCSV, Methrom 663 stand, MicroAutolab II) (Croot and Johansson 2000). Iron concentration was measured, in triplicate, after UV photo-oxidation ( $1 \mathrm{~kW}$ for $5 \mathrm{~h}$ ), $\mathrm{pH}$ adjustment to 8.1 using $\mathrm{NH}_{4} \mathrm{OH}$ (Ultrex grade; Seastar), and standard Fe addition. Destruction of organic compounds by UV photo-oxidation was verified for the hydroxamate siderophore desferrioxamine B (Sigma). The accuracy of total Fe determination was checked using the certified NASS-5 sample (certified at 3.71 \pm $0.63 \mathrm{nM}$ Canadian Research Council, measured at $3.45 \pm 0.07$, $n=6)$ and an in-house Antarctic seawater standard collected for intercalibration at $46.4^{\circ} \mathrm{S} 140.5^{\circ} \mathrm{E}, 700 \mathrm{~m}$ depth $(0.31 \pm$ $0.03, n=3$, in agreement with measurement using flow injection and CLE-AdCSV; D. Lannuzel and E. Ibisanmi, unpublished observations). The dissolved Fe (before ${ }^{55} \mathrm{Fe}$ addition) concentrations were $0.34 \pm 0.05 \mathrm{nM}$ in SO, $0.52 \pm 0.01 \mathrm{nM}$ in Aquil, and $10.5 \pm 0.2 \mathrm{nM}$ in Woodbridge. For freshwater, the nominal Fe concentration in the experimental Fraquil solution $(100 \mathrm{nM})$ was used.

Washing agents-We studied the ability of three washing agents to remove surface-adsorbed (i.e., extracellular) Fe. TiEDTA was prepared and used as recommended by Hudson and Morel (1989), DTPA (Sigma) was applied at a concentration of $1 \mathrm{mM}(\mathrm{pH} 7.0)$, and oxalate was prepared according to Tang and Morel (2006) (100 mM NaCl, $10 \mathrm{mM} \mathrm{KCl,} 100$ $\mathrm{mM} \mathrm{Na}_{2}$ oxalate, and $50 \mathrm{mM} \mathrm{Na}_{2}$ EDTA, $\mathrm{pH}$ 7.0) for seawater and according to Tovar-Sanchez et al. (2003) (with reducedsalinity $100 \mathrm{mM} \mathrm{Na}_{2}$ oxalate, $50 \mathrm{mM} \mathrm{Na}$ citrate, and $50 \mathrm{mM}$ $\mathrm{Na}_{2}$ EDTA, pH 7.1) for freshwater. Because phosphate levels are higher in eutrophic lakes (such as Lake Champlain; Young and Ross, 2001) than seawater, the citrate was kept for freshwater experiments to improve phosphate (and Feassociated) removal. A concentrated sodium hydroxide solution $(5 \mathrm{M})$ was used to adjust the $\mathrm{pH}$ of the oxalate washing solution. All chemicals were ACS reagent grade or higher (Sigma-Aldrich).
Oxalate directly applied in solution

\author{
Oxalate applied
} on the filter

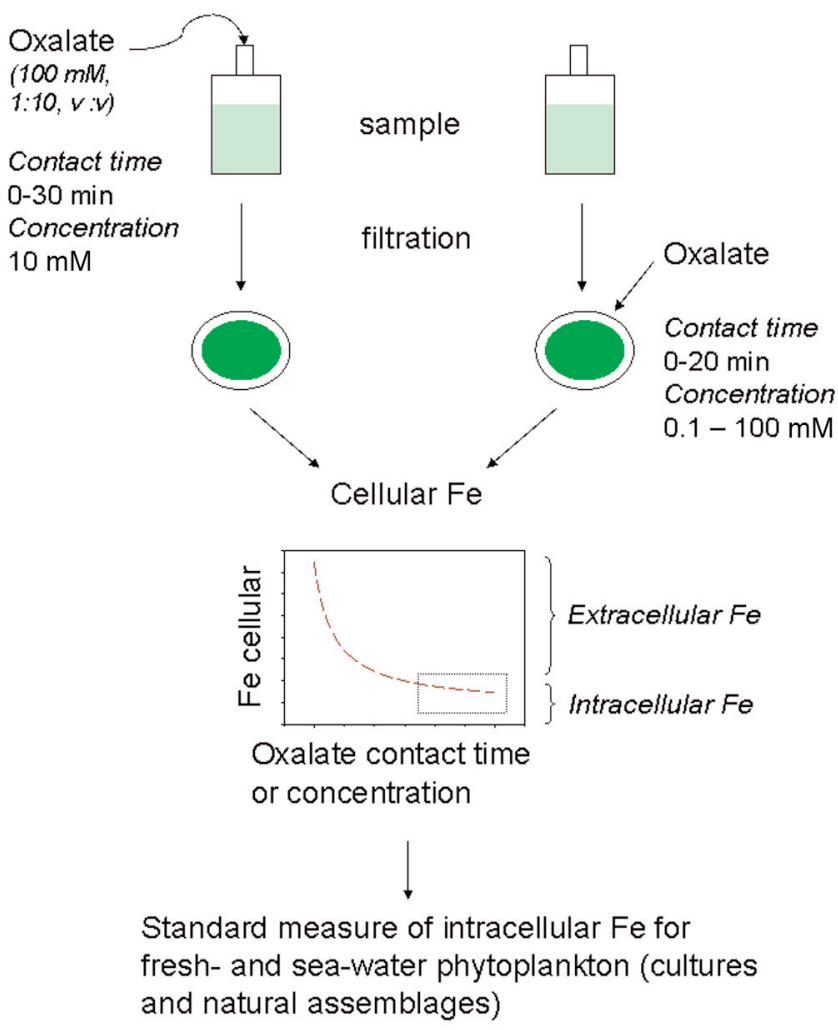

Fig. 1. Schematic representation of the experiments performed. Two modes of application of oxalate were tested: directly in the solution or on the filter after filtration. The decreased particulate or cellular iron as a function of contact time and the concentration of oxalate applied was used to discriminate extracellular from intracellular iron. In an attempt to propose a standard use of the oxalate wash, marine and freshwater plankton cultures and natural assemblages were used.

The effect of contact time (0-35 min) was assessed for all fresh- and seawater model and natural phytoplankton. The effect of the concentration of oxalate $(0.1$ to $100 \mathrm{mM})$ in the oxalate solution was determined on freshwater phytoplankton. Finally, the amendment of oxalate, either on the filter or directly into the algal suspension (dilution 1:10 vol:vol), was assessed for seawater plankton (see Fig. 1).

Biological effect of the oxalate treatment-An aliquot of Chaetoceros sp. exponentially growing in Aquil media $\left(4^{\circ} \mathrm{C}, 20\right.$ $\mu \mathrm{mol}$ quanta $\mathrm{m}^{-2} \mathrm{~s}^{-1}$ following a $18 \mathrm{~h}: 6 \mathrm{~h}$ light:dark cycling) was sampled in a 10-mL polycarbonate tube. A 1:10 vol:vol chelexed $\mathrm{NaCl}(0.6 \mathrm{M})$ or oxalate $(\mathrm{pH} 7.0)$ solution was added, and tubes were kept at $4^{\circ} \mathrm{C}$ under $50 \mu \mathrm{mol}$ quanta $\mathrm{m}^{-2}$ $\mathrm{s}^{-1}$ for $20 \mathrm{~min}$. The algal suspension was then gently filtered (20- $\mu \mathrm{m}$ polycarbonate filter), rinsed five times with $3 \mathrm{~mL}$ Aquil media, and resuspended in Aquil. Growth of the Chaetoceros in Aquil was measured using an electronic particle counter (Coulter counter; Multisizer Z2). Experiments were done in triplicate. 
Experimental precautions-To avoid Fe contamination, all model phytoplankton cultures were manipulated inside a class-100 laminar flow hood. Exclusively acid-washed plastic materials (containers, filters, filtration devices) were used, as described elsewhere (e.g., Schoemann et al. 2001, Hassler et al. 2004). Aquil and Fraquil solutions were sterilized using microwaves, and the absence of bacterial contamination was regularly verified on an agar plate and using epifluorescent microscopy following DAPI staining (on 30 to $50 \mathrm{~mL}$ culture). The significance of the differences between treatments was assessed using a two-tailed paired Student $t$ test at the 95\% confidence level.

\section{Assessment}

Assuming that the Eigen-Wilkens mechanism applies (see Morel and Hering 1993), then the limiting step for the complexation reaction is the loss of a water molecule from the inner coordination sphere (described by the metal-dependent constant $k_{-\mathrm{w}}$ ). The time required for Fe desorption can therefore be assessed. Based on an average $k_{-\mathrm{w}}$ of $10^{-3} \mathrm{~s}^{-1}$ (Morel and Hering 1993) for Fe(III) and a stability constant for the outersphere complex, $K_{\text {os, }}$ of $10^{0.28} \mathrm{~L} \mathrm{M}^{-1}$ for Fe(III) reacting with a single anionic ligand in seawater (Morel and Hering 1993), a maximum forward constant rate $\left(k_{\mathrm{f}}\right.$, defined as $\left.K_{\mathrm{os}} \times k_{-\mathrm{w}}\right)$ of 1.9 $\times 10^{3} \mathrm{~L} \mathrm{M}^{-1} \mathrm{~s}^{-1}$ can be estimated for Fe(III). An average affinity constant for $\mathrm{Fe}(\mathrm{III})$ at the surface of Thalassiosira weissflogii in seawater ( $K_{\mathrm{MS}}$ given by inverse of Michaelis-Menten constant) of $10^{17.9} \mathrm{M}^{-1}$ has been reported (Harrison and Morel 1986; Hudson and Morel 1990). Using both $k_{\mathrm{f}}$ and $K_{\mathrm{MS}}$, a maximum predicted value for the reverse rate constant $\left(k_{\mathrm{d}}\right)$ of $2.4 \times 10^{-15}$ $\mathrm{s}^{-1}$ can be calculated for Fe(III), corresponding to a turnover rate of $1.3 \times 10^{7}$ years for $\mathrm{Fe}(\mathrm{III})$, demonstrating that simple thermodynamics and surface complexation considerations cannot explain the removal of Fe observed by using oxalate or Ti-EDTA solutions (Hudson and Morel 1989, Tovar-Sanchez et al. 2003, Tang and Morel 2006). The small $k_{\mathrm{d}}$ for Fe and biological surfaces was supported (i) by the observation that Fe bound to the surface of the coccolithophorid Pleurochrysis carterae is being accumulated, rather than released, into the experimental solution, even at high Fe concentrations of 100 nM (Hudson and Morel 1990), and (ii) by the inability of single ligands such as NTA, EDTA, or DTPA to efficiently remove extracellular Fe (Hudson and Morel 1990, Tang and Morel 2006, this study). Inorganic complexation can increase the apparent chemical reactivity of Fe. For example, a much smaller $k_{\mathrm{d}}\left(2.4 \times 10^{-1} \mathrm{~s}^{-1}\right)$ can be calculated when considering that $\mathrm{Fe}(\mathrm{III})^{\prime}$ is reacting with biological surface (average $k_{-\mathrm{w}} 10^{-7}$ $\mathrm{s}^{-1}, K_{\mathrm{MS}}=10^{7.9} \mathrm{M}^{-1}$, assuming a partition coefficient between $\mathrm{Fe}(\mathrm{III})^{\prime}$ and Fe(III) of 10 ${ }^{10}$; Hudson et al. 1992, Morel and Hering 1993). Redox processes can also fasten the desorption or solubilization of Fe from inorganic and biological surfaces, since $\mathrm{Fe}(\mathrm{II})$ has an average $k_{-\mathrm{w}} 1250$-fold smaller than that of Fe(III) (Morel and Hering 1993). In such cases, Fe uptake and desorption would be controlled by the formation kinetics of the Fe-MS, whereby both Fe(III)' and Fe(II) need to be considered as supported by previous studies (e.g., Hudson and Morel 1990, Shaked et al. 2005).

An efficient washing agent such as Ti-EDTA relies on both redox potential and strong binding affinity for Fe(III), whereas the oxalate wash mainly relies on Fe surface chelation (Tang and Morel 2006). Previous studies on the dissolution of colloidal Fe (hydr)oxides show that oxalate is a suitable ligand because of the formation of surface ternary complex Fe(III)oxide-oxalate-Fe(II) acting as an electron bridge for electron transfer from Fe(III) to Fe(II) (Sulzberger et al. 1989). Oxalate solution, as used in this study, can result in significant Fe(hydr)oxides dissolution by three pathways acting synergistically (Sulzberger et al. 1989, Borer et al. 2005): (1) surface chelation, (2) $\mathrm{Fe}(\mathrm{II})$-catalyzed dissolution in the presence of other chelating agent (e.g., EDTA), and (3) light-induced dissolution in presence of electron donor (e.g., oxalate). In this case, the Fe desorption efficiency could not be predicted solely using the Eigen-Wilkens theory and the affinity of the washing agent for Fe(III), as opposed to previous observations for other transition metals (Hassler et al. 2004). Nonetheless, similar desorption kinetics are expected, with most of the Fe desorption occurring over a short period in contact with washing solution and the attainment of a plateau representing the intracellular pool of Fe. The intracellular pool of Fe is not accessible to the washing agent, since it is kept outside the microorganism and does not damage cell integrity (see below).

Effect of contact time with oxalate solution-We assessed the efficiency of desorption and dissolution via the decrease of particulate Fe due to the application of the washing treatment for various contact times compared to the initial particulate Fe measured after three rinses with nonradioactive experimental solution without any oxalate treatment. For all plankton and water tested, a fast decrease of particulate Fe is observed with increased contact time. For contact time $\geq 20 \mathrm{~min}$, particulate Fe values reach a plateau corresponding to intracellular Fe and to maximal desorption and dissolution of extracellular Fe (Fig. 2). Accurate estimation of intracellular Fe after washing treatment for $20 \mathrm{~min}$ in seawater (Fig. 2C and D) is further supported by the nonsignificant difference between the oxalate wash for $20 \mathrm{~min}$ and the Ti-EDTA wash for $2 \mathrm{~min}$ (Table 1), as well as particulate Fe obtained for longer contact time in the Aquil medium or estuary samples (Fig. 2E and F, see below). The various levels of intracellular Fe are the result of variable Fe uptake rates and mechanisms, both of which depend on biota and water chemistry (e.g., Hassler and Wilkinson 2003, Hassler et al. 2004). In the present study, the oxalate wash requires a minimum contact time of 20 min to efficiently desorb and solubilize the extracellular Fe, regardless of the type of phytoplankton considered. Therefore, all further assessment of the oxalate wash was done using a constant contact time of $20 \mathrm{~min}$. Intracellular Fe uptake rates, as measured after a 20-min oxalate wash, are shown in Table 2. Cellular Fe was normalized per Chl $a$ for natural plankton 


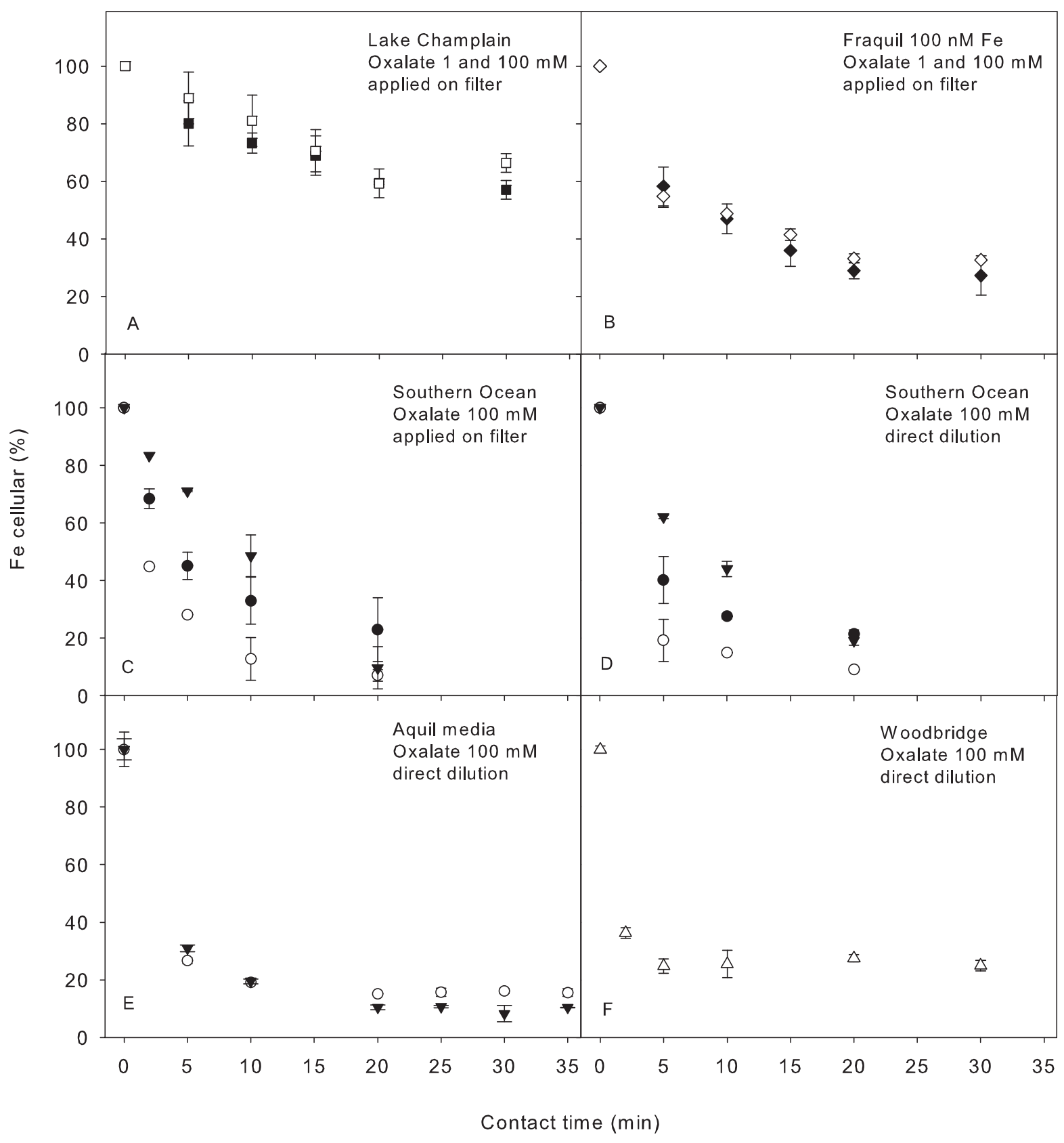

Fig. 2. Effect of contact time, concentration, and delivery of oxalate solution ( $\mathrm{pH} 7)$ on cellular Fe content for freshwater (A and $B)$ and seawater (C, $D$, $\mathrm{E}$, and F) phytoplankton. Freshwater phytoplankton are natural assemblages from Lake Champlain ( $\square$ and $\square$ ) and $S y n e c h o c o c c u s s p$. ( $\diamond$ and $\diamond)$, where the oxalate concentration applied was $100 \mathrm{mM}$ (filled symbol) and $1 \mathrm{mM}$ (open symbol). Seawater phytoplankton are natural assemblages from the Southern Ocean $(\bullet)$, Derwent River estuary $(\triangle)$, Phaeocystis sp. $(\mathrm{O})$, and Chaetoceros $s p$. ( $\boldsymbol{\nabla})$. Iron solubilization by oxalate applied on the filter (A-C) and directly into algal suspension (D-F) was studied in natural water (A, B, C, F) and in synthetic inorganic growth media (B and E). Oxalate washing was performed during 0 to $30 \mathrm{~min}$. Error bars represent standard deviations $(n=3)$.

community and per cell for model phytoplankton. Given that Fe status (limitation and biological requirement) are probably different for all the strains and communities studied here, and that pigments and uptake strategies can be influenced by $\mathrm{Fe}$ limitation (e.g., Wilhelm 1995, Van Leeuwe and Stefels 1998, Völker and Wolf-Gladrow 1999), results obtained could not be quantitatively compared.
Effect of the nature of the washing agent-The extraction efficiencies of the oxalate and Ti-EDTA solutions (20 min contact time for oxalate and 2 min for Ti-EDTA; Table 1) were obtained by comparison with the initial internalized Fe after three rinses with a nonradioactive experimental solution only. DTPA, while having an affinity constant several orders of magnitude higher than that of EDTA in both seawater and 
Table 1. Effect of the nature of the washing agent on the estimation of intracellular Fe for phytoplankton after a 20-min contact time, except for the Ti-EDTA wash, where a 2-min contact time was applied as recommended by Hudson and Morel (1989).

\begin{tabular}{|c|c|c|c|c|}
\hline & \multicolumn{4}{|c|}{ Intracellular $\mathrm{Fe}, \%$ of control $\pm \mathrm{SD}(n=3)$} \\
\hline & $P$ & Oxalate & DTPA, $1 \mathrm{mM}$ & Ti-EDTA \\
\hline Freshwater phytoplankton & 0.004 & $55.4 \pm 5.6$ & $91.2 \pm 10.4$ & - \\
\hline Synechococcus PCC 7942 & 0.088 & $32.5 \pm 1.3$ & $53.1 \pm 15.5$ & - \\
\hline Seawater phytoplankton & 0.862 & $23.0 \pm 11.0$ & - & $24.1 \pm 1.3$ \\
\hline Chaetoceros sp. & 0.063 & $9.7 \pm 7.3$ & - & $4.9 \pm 0.8$ \\
\hline Phaeocystis sp. & 0.407 & $7.1 \pm 2.1$ & - & $4.8 \pm 2.1$ \\
\hline
\end{tabular}

Washing solution was applied on the filter.

Table 2. Average Fe uptake rate $(n=3)$ expressed in $[\mathrm{Fe}]_{\mathrm{int}} / \mathrm{Chl} a\left(\mathrm{nmol} \mathrm{Fe} \mu \mathrm{g} \mathrm{Chl} a^{-1} \mathrm{~h}^{-1}\right)$ for natural and model phytoplankton.

\begin{tabular}{lccc}
\hline Plankton & Media & {$[\mathrm{Fe}]_{\text {int }} / \mathrm{Chl} \boldsymbol{a}, \mathbf{n m o l ~} \boldsymbol{\mu g} \mathrm{Chl} \boldsymbol{\sigma}^{-1} \mathbf{h}^{-1}$} & Fe:C, $\boldsymbol{\mu m o l : m o l}$ \\
\hline Synechococcus & Fraquil & $2.04 \pm 0.24$ & - \\
Natural & SO & $13.2 \pm 1.52$ & $18.4 \pm 1.33$ \\
Chaetoceros & SO & $2.47 \pm 0.21$ & $23.5^{\mathrm{a}}$ \\
Phaeocystis & SO & $1.80 \pm 0.13$ & $21.4^{\mathrm{a}}$ \\
Chaetoceros & Aquil & $1.05 \pm 0.08$ & - \\
Phaeocystis & Aquil & $2.08 \pm 0.06$ & - \\
Natural & Woodbridge & $0.78 \pm 0.04$ & - \\
\hline
\end{tabular}

Results are after 20-min treatment on filter (Synechococcus) or 1:10 vol:vol direct dilution (all others). Iron-to-carbon ratios (Fe: $\mathrm{C}$, $\mu$ mol:mol) are given only for natural phytoplankton from the Southern Ocean (SO), where carbon uptake was also measured. Natural Chl $a$ content ( $\mu \mathrm{g} \mathrm{L} \mathrm{L}^{-1}$ ) was 0.4 for SO and 0.5 for Woodbridge. Cellular Chl $a$ was taken from Hassler et al (2006) for Synechococcus (15 fg Chl $a$ per cell) and from HPLC measurement for Chaetoceros (131 fg Chl $a$ per cell) and Phaeocystis (167 fg Chl $a$ per cell) for cell acclimated to SO water as used in this study (C. Hassler, unpublished). aAverage Fe:C ratio measured with Chaetoceros and Phaeocystis in Antarctic water ( $1 \mathrm{nM}[\mathrm{Fe}]_{\mathrm{tot}^{\prime}} 68^{\circ} \mathrm{S} 55^{\circ} \mathrm{W}$ ) is also shown (V. Schoemann and C. Hassler, unpublished data).

freshwater (NIST v. 8.0), did not succeed in desorbing all Fe bound to the surface of freshwater phytoplankton. The oxalate treatment can decrease the biogenic pool of Fe from Lake Champlain by a further $20 \%$ to $36 \%$. In contrast, the washing efficiencies for the oxalate and the DTPA solutions are not statistically different for Synechococcus sp., despite very different average cellular Fe concentrations. This is probably due to the large standard deviation in the cellular Fe measurement observed after the washing with DTPA. The oxalate wash efficiently removed adsorbed and freshly oxidized Fe, giving similar results to the Ti-EDTA washing for seawater plankton. In this case, a 20-min wash of phytoplankton gives an accurate estimate of the intracellular pool of Fe.

Effect of the oxalate concentration-Because the "clean" oxalate solution still contains a significant amount of Fe (17 $\mathrm{nM}$ found by Tovar-Sanchez et al. 2003; $11 \mathrm{nM}$ as measured by ICP-MS in this study), we tested the washing efficiency using variable oxalate concentrations (0.01 to $100 \mathrm{mM}$ ) (Table 3). The dissolution efficiency of extracellular Fe was assessed by comparison with the initial internalized Fe (see above). For both Synechococcus and freshwater natural phytoplankton, a slight, but statistically significant, increase in the washing efficiency was observed using $100 \mathrm{mM}$ compared to $0.01 \mathrm{mM}$ oxalate. Nonetheless, the oxalate concentration could be decreased from $100 \mathrm{mM}$ to $1 \mathrm{mM}$ for natural phytoplankton, and to $0.1 \mathrm{mM}$ for Synechococcus, without significantly affecting the intracellular Fe pool. Consequently, $1 \mathrm{mM}$ oxalate appears to be sufficient to promote an efficient solubilization of freshly oxidized Fe and Fe bound to the surface of phytoplankton. A statistically similar decrease of cellular Fe as a function of the contact time was observed for both 100 and 1 mM oxalate for Lake Champlain (Fig. 2A) and for Synechococcus (Fig. 2B). The only difference was observed after 30-min contact time in Lake Champlain, where treatment with $1 \mathrm{mM}$ oxalate resulted in slightly $(5 \%, P=0.025)$ higher cellular Fe. However, no difference was observed between cellular Fe following a 20-min $1 \mathrm{mM}$ oxalate treatment and following a 20to 30 -min $100 \mathrm{mM}$ oxalate treatment.

Effect of the oxalate amendment method-Given the fact that the oxalate concentration could be reduced without affecting the washing efficiency of the extracellular Fe, the direct application of oxalate in the algal suspension was tested, resulting in a final concentration of $10 \mathrm{mM}$ oxalate (Fig. 2D-F). The direct application of oxalate provides an easy, accurate control on the timing of termination of the intracellular Fe uptake. This is an advantage, particularly for experiments involving manipulations longer than 5 to $10 \mathrm{~min}$, such as size fractionation of algal suspensions before the oxalate treatment. 
Table 3. Effect of the concentration of oxalate applied for the estimation of intracellular Fe in freshwater phytoplankton after a 20-min contact time $(n=3-6)$.

\begin{tabular}{lcc}
\hline & \multicolumn{2}{c}{ Intracellular Fe, \% of control \pm SD $(\mathbf{n}=3)$} \\
\cline { 2 - 3 } Oxalate, $\mathrm{mM}$ & $\begin{array}{c}\text { Freshwater } \\
\text { phytoplankton }\end{array}$ & $\begin{array}{c}\text { Synechococcus } \\
\text { PCC 7942 }\end{array}$ \\
\hline 0.01 & $67.5 \pm 0.9(0.016)$ & $36.7 \pm 1.4(0.006)$ \\
0.1 & $69.2 \pm 3.5(0.009)$ & $36.0 \pm 3.4(0.094)$ \\
1 & $60.8 \pm 3.7(0.066)$ & $36.4 \pm 2.7(0.052)$ \\
10 & $59.6 \pm 4.2(0.084)$ & $36.5 \pm 2.8(0.056)$ \\
100 & $55.4 \pm 5.6$ & $32.5 \pm 1.3$ \\
\hline
\end{tabular}

Washing solution was applied on the filter.

In addition, the direct application of oxalate in the experimental solution offers the advantage of a homogeneous washing of all sizes of phytoplankton present. This becomes highly relevant for phytoplankton $>5 \mu \mathrm{m}$. Indeed, it is impossible to maintain the oxalate solution on filters $>5 \mu \mathrm{m}$ for $20 \mathrm{~min}$. The oxalate solution passes rapidly by gravity. In this case, the oxalate treatment cannot be well controlled, and oxalate has to be applied several times, resulting in an inhomogeneous washing procedure compared with smaller size fractions (C.S. Hassler and V. Schoemann, personal observation). Such a problem could be resolved using "clips" downstream of the filtration; however, this would not be suitable for radioisotope experiments and could be critical for in situ particulate $\mathrm{Fe}$ determination, as it would increase the chance for background contamination. No statistical difference was observed at any contact time for oxalate applied on the filter (Fig. 2C) or in the experimental solution (Fig. 2D), except for Chaetoceros sp. after 5-min contact time $(P=0.0007)$.

Influence of water chemistry-The direct application of the oxalate solution was tested for Chaetoceros sp. and Phaeocystis sp. exposed to synthetic seawater (Aquil without any micronutrients, Fig. 2E) and filtered SO water (Fig. 2D). For both model phytoplanktons, a faster dissolution of extracellular Fe was observed in Aquil, probably because of the absence of aged oxides and organic matter in the Aquil media. The consistency of the results after 20-min contact with the oxalate solution strengthens our assessment that 20-min contact time is generally required to accurately measure intracellular Fe (see also above).

In estuary water, with higher particle content and Fe concentration well above its maximal solubility, colloids are thought to be less reactive in the Southern Ocean. Oxalate was found less efficient at solubilizing more stable Fe(hydr)oxides, probably because of a fast reoxidation of the Fe on the oxides surface (Sulzberger and Laubscher 1995). In this case, for the estuary sample (Fig. 2F), a slower decrease of Fe with oxalate contact time is expected compared to that observed in Aquil (Fig. 2E) and the pelagic Southern Ocean (Fig. 2D). Surprisingly, a fast decrease of cellular Fe was observed with no further statistical decrease after 5-min contact time. To verify the efficiency of the oxalate solution to dissolve stable Fe oxides, sterile $\left(0.2 \mu \mathrm{m}\right.$ filtered) water was equilibrated with ${ }^{55} \mathrm{Fe}$ for 72 h. Colloidal and particulate Fe was then assessed by the radioactivity retained on a $0.2-\mu \mathrm{m}$ filter. Twenty-minute oxalate treatment (direct dilution) decreased only $>0.2 \mu \mathrm{m} \mathrm{Fe}$, from $1.65 \pm 0.00 \mathrm{nM}$ down to $0.48 \pm 0.01 \mathrm{nM}$. In this case, oxalate was poorly efficient to remove radiolabeled Fe preequilibrated to naturally occurring inorganic or organic Fe colloids/particles.

Biological effect of a 20-min oxalate wash-Growth curves and growth parameters were identical (Table 4) for Chaetoceros $s p$. treated for $20 \mathrm{~min}$ in oxalate and $\mathrm{NaCl}$, attesting to the absence of significant biological deleterious effect as a result from an exposure to 1:10 vol:vol oxalate solution at $\mathrm{pH}$ 7. Lag phase was slightly longer for Chaetoceros $s p$. that were oxalatetreated, attesting to minor biological stress associated with exposure to the oxalate solution. However, the final biomass at early stationary phase was slightly higher for the oxalatetreated cells. Given that cells treated with oxalate were rinsed three times with $5 \mathrm{~mL}$ Aquil before resuspension in the Aquil, no significant oxalate was relocated in the growth media. The slightly higher final biomass observed for cells treated with oxalate was thus attributed to small differences in the initial cell density. As previously observed for 5- to 10-min exposure (Tovar-Sanchez et al. 2003, Tang and Morel 2006), a 20-min exposure to the oxalate solution did not result in deleterious biological effect for an Antarctic diatom.

\section{Discussion}

Despite the recommended use of oxalate solution to discriminate between the intracellular and extracellular pools of Fe associated with phytoplankton, efficiencies of desorption were previously reported only for Thalassiosira weissflogii. Our results show that the 5- to 10-min contact time recommended (Tovar-Sanchez et al. 2003, Tang and Morel 2006) is not sufficient, but that 20-min contact time provides a more accurate measurement of the intracellular pool of Fe associated with phytoplankton present in both freshwater and seawater. The use of oxalate solution has been shown to be less successful in removing particulate abiotic ferric oxyhydroxides than TiEDTA (90\% and 99\% Fe removal with oxalate and Ti-EDTA washing techniques, respectively; Tang and Morel 2006). Given that colloidal Fe is ubiquitous (Wu et al. 2001), the use of oxalate could lead to a slight overestimation of biogenic particulate Fe in natural waters. Nonetheless, the similar intracellular Fe measured using treatments with 2-min Ti-EDTA and 20-min oxalate in waters from the Southern Ocean (this study) suggests that the oxalate wash procedure results in an accurate estimate of the intracellular Fe pool in HNLC regions of the oceans. Oxalate treatment for $20 \mathrm{~min}$, however, removed only ca. $70 \%$ of the abiotic colloidal and particulate Fe in the Woodbridge water, showing that oxalate has to be used with caution in environments rich in colloids and particles and where dissolved Fe is much higher than its solubility 
Table 4. Determination of growth parameter for Chaetoceros $s p$. in Aquil after treatment in oxalate $(\mathrm{pH} 7.0)$ and $\mathrm{NaCl}(0.6 \mathrm{M})$ solutions in 1:10 vol:vol for 20 min $(n=3-9)$.

\begin{tabular}{|c|c|c|c|c|}
\hline Treatment & $\mu$, days $^{-1}$ & Lag phase, days & Diameter, $\mu \mathrm{m}$ & Biomass, $\times 10^{6}$ cells $/ \mathrm{mL}$ \\
\hline $\mathrm{NaCl}$ & $0.46 \pm 0.02$ & 9 & $5.00 \pm 0.29$ & $1.44 \pm 0.03$ \\
\hline Oxalate & $0.45 \pm 0.01$ & 11 & $5.18 \pm 0.23$ & $1.58 \pm 0.07$ \\
\hline
\end{tabular}

Treatment was applied at $4^{\circ} \mathrm{C}$ under $50 \mu \mathrm{mol}$ quanta $\mathrm{m}^{-2} \mathrm{~s}^{-1}$, and growth was followed at $4^{\circ} \mathrm{C}$ under $20 \mu \mathrm{mol}$ quanta $\mathrm{m}^{-2} \mathrm{~s}^{-1}$ in a $16 \mathrm{~h}: 8 \mathrm{~h}$ light:dark cycle using a Coulter counter.

limit. Addition of a reducing agent such as ascorbate might improve Fe solubilization of stable Fe oxides, as reported in Sulzberger et al. (1989). The comparison between Ti-EDTA and oxalate wash for coastal waters and freshwaters, which contain higher concentrations of $\mathrm{Fe}$ and organic matter, needs further attention. In this case, it could be recommended to apply short-term incubations to reduce the formation of particulate and colloidal ${ }^{55} \mathrm{Fe}$ insoluble with the oxalate treatment. It is also important to note that the presence of microorganisms will favor kinetics (Morel and Hering 1993, Wilkinson and Buffle 2004). Radiolabeled Fe should thus remain strongly reactive upon oxalate addition during shortterm uptake experiments.

Taking into account an average Fe:Al crustal ratio of 0.04 (Wedepohl 1995), it was demonstrated that lithogenic Fe was successfully distinguished from biogenic Fe for samples collected in the Southern Ocean after an oxalate wash (TovarSanchez et al. 2003). In this case, a 20-min wash with trace metal-clean oxalate (as recommended in this study), followed by rinsing with trace metal-clean filtered seawater or a chelexed $\mathrm{NaCl}$ solution $\left(\mathrm{NaCl} 0.6 \mathrm{M}\right.$ and $\mathrm{NaHCO}_{3} 2.38 \mathrm{mM}$, as recommended by Tang and Morel 2006) would be the only existing procedure to accurately assess biogenic stoichiometric Fe:C or Fe:N ratios in Fe-limited HNLC waters. Another alternative would be preparing the oxalate solution using ultraclean $\mathrm{NH}_{4} \mathrm{OH}$ rather than $\mathrm{NaOH}$ as originally recommended in Tovar-Sanchez et al. (2003). Presently, the Fe:C ratios reported in HNLC waters vary by more than two orders of magnitude (from $5 \times 10^{-3}$ to more than $5 \times 10^{-5}$; Boyd et al. 2007), which renders accurate modeling of $\mathrm{C}$ export in Fe-limited HNLC regions of the ocean quite challenging. Finally, the stoichiometric ratios between Fe and plankton biomass (as C, $\mathrm{P}$, or $\mathrm{N}$ ) measured in the field are critical to understand how Fe bioavailability controls phytoplankton distribution, abundance, primary productivity, C export, and ultimately climate variation (Boyd et al. 2007).

In this study, a Fe:C of 18.4 (Table 4) was reported for natural plankton from the Southern Ocean, a region where primary productivity is known to be limited by Fe (Boyd et al. 2007). This ratio is in good accordance with other Fe:C ratios measured in the SO using oxalate (Table 4, Chaetoceros sp. and Phaeocyctis sp.; C.S. Hassler and V. Schoemann, unpublished data; Tovar-Sanchez et al. 2003), Ti-EDTA (Maldonado et al. 2005), and synchrotron-based X-ray fluorescence (Twining et al. 2004). In addition, the oxalate wash can successfully relate the intracellular pool of numerous metals (Fe, $\mathrm{Cu}, \mathrm{Zn}, \mathrm{Co}, \mathrm{Cd}$, and Mn; Tang and Morel 2006) without deleterious biological effects (Tovar-Sanchez et al. 2003, Tang and Morel 2006). Given that intracellular pools of the divalent metals $\mathrm{Cu}, \mathrm{Zn}$, Co, and Cd can be measured using a milder wash (typically EDTA; Hassler et al. 2004), the stronger oxalate wash should be at least as efficient in distinguishing their respective intracellular pools. Although trace metals (other than Fe) have been reported to influence or limit primary productivity in some parts of the ocean (e.g., for $\mathrm{Zn}$ and Co; Saito et al. 2002, Leblanc et al. 2005, Saito and Goepfert 2008), this subject is still poorly documented. The oxalate wash, coupled with multi-element detection, can therefore allow the gathering of new knowledge identifying whether the planktonic biomass is limited or colimited by other trace metals.

\section{Comments and recommendations}

Although the same contact time of 20 min provides an accurate measurement of intracellular Fe for all of the phytoplankton tested here, it is difficult to give a universal procedure, given the highly variable water chemistry and surface binding groups present in phytoplankton. For this reason, future studies determining intracellular Fe pools need to explicitly include the kinetics of the Fe solubilization. This will need both quality control of the determination of intracellular Fe and increased knowledge toward a universal procedure to discriminate intracellular from extracellular Fe.

Based on the results of this study, direct amendment of oxalate in the experimental solution presents many advantages compared with oxalate treatment on the filter. Given that a 20-min contact time with oxalate is required to efficiently solubilize Fe for fresh- and seawater phytoplankton, filtration of the sample and subsequent treatment with oxalate on the filter would be time-consuming and would significantly restrain the number of samples that could be processed within a given time frame (for instance, during an oceanographic expedition). To maintain the oxalate solution above filters with a large pore size ( $>5 \mu \mathrm{m}$ ) for $20 \mathrm{~min}$, either a larger volume of oxalate solution, or successive additions, are required, resulting in nonhomogeneous washing procedures for the various pore size filters. This can be problematic for the interpretation of size-fractionated intracellular Fe pools. The direct amendment of the oxalate in the experimental solution presents many advantages: homogeneity of the washing procedure, better control of the bioaccumulation termination, 
and significant gain of time. Therefore, a procedure using the direct application of the oxalate to the experimental solution is recommended. In this case, the sample can be split into two parts before being processed: (a) for the analysis of total particulate and dissolved $\mathrm{Fe}$, and (b) for the analysis of intracellular Fe. During the 20-min contact times required in (b), samples for (a) can be processed. Such an experimental procedure allows for the processing of an increased number of samples on a single filtration unit, given that each filtration device is used solely for filtering, rather than for both the filtration and the oxalate wash. However, a higher volume of oxalate solution is required. Because oxalate reagents are cheap and the preparation of the solution is rapid, the higher volume requirements should not be problematic when working with radiolabeled Fe. However, to measure the concentration of particulate $\mathrm{Fe}$ in situ (i.e., nonradiolabeled) for the determination of the stoichiometric ratio of Fe to $\mathrm{C}$, trace metal-clean oxalate solution is needed. Such measurements are time-consuming, as they require the filtration of large volumes of water (e.g., >5 L). In this case, because of the time required to prepare large volumes of trace metal-clean oxalate solution, the application of oxalate solution on the filter would be preferred.

In an attempt to improve the contact time, or minimize the oxalate concentration required, successive oxalate washing could be used as in Tang and Morel (2006). After the first wash, a significant proportion (20\%-80 \%) of Fe was removed, thus increasing the ratio of free ligands (oxalate and EDTA, in this case) compared to reactive (i.e., extracellularly adsorbed) Fe during the second wash, favoring a more efficient Fe desorption/removal (see Hassler et al. 2004).

\section{References}

Berges, J. A., D. J. Franklin, and P. J. Harrison. 2001. Evolution of an artificial seawater medium: improvements in enriched seawater, artificial water over the last two decades. J. Phycol. 37:1138-1145.

Borer, P. M., B. Sulzberger, P. Reichard, and S. M. Kraemer. 2005. Effect of siderophores on the light-induced dissolution of colloidal iron(III) (hydr)oxides. Mar. Chem. 93:179193.

Boyd, P. W., and others. 2007. Mesoscale iron enrichment experiments 1993-2005: synthesis and future directions. Science 315:612-617.

Boye, M., C. M. G. van den Berg, J. T. M. de Jong, H. Leach, P. Croot, and H. J. W. de Baar. 2001. Organic complexation of iron in the Southern Ocean. Deep-Sea Res. Part I Oceanogr. Res. Pap. 48:1477-1497.

Chen, M., and Wang, W.-X. 2004. Phase partitioning and solubility of iron in natural seawater controlled by dissolved organic matter. Global Biogeochem. Cycles 18:GB4013, doi:10.1029/2003GB002160.

Croot, P. L., and M. Johansson. 2000. Determination of iron speciation by cathodic stripping voltammetry in seawater using the competing ligand 2-(2-thiazolylazo)-p-cresol (TAC). Electroanalysis 12:565-576.

-, K. Andersson, M. Öztürk, and D. R. Turner. 2004. The distribution and speciation of iron along $6^{\circ} \mathrm{E}$ in the Southern Ocean. Deep-Sea Res. Part II Oceanogr. Res. Pap. 51:2857-2879.

De Baar, H. J. W., and J. T. M. de Jong, 2001. Distribution, sources and sinks of iron in seawater. In: D. R. Turner and K. H. Hunter [eds.], The Biogeochemistry of Iron in Seawater, IUPAC Series on Analytical and Physical Chemistry of Environmental Systems, vol. 7, p. 123-253.

DiTullio, G. R., and others. 2000. Rapid and early export of Phaeocystis antarctica blooms in the Ross Sea, Antarctica. Nature 404:595-598.

Harrison, P. J., R. E. Waters, and F. J. R. Taylor. 1980. A broad spectrum artificial seawater medium for coastal and open ocean phytoplankton. J. Phycol. 16:28-35.

Harrison, G. I., and F. M. M. Morel. 1986. Response of the marine diatom Thalassiosira weissflogii to iron stress. Limnol. Oceanogr. 31:989-997.

Hassler, C. S., and K. J. Wilkinson. 2003. Failure of the biotic ligand and free-ion activity models to explain zinc bioaccumulation by Chlorella kesslerii. Environ. Toxicol. Chem. 22:620-626.

—, V. I. Slaveykova, and K. J. Wilkinson. 2004. Discriminating between intra- and extracellular metals using chemical extractions. Limnol. Oceanogr. Meth. 2:237-247.

—, M. R. Twiss, R. M. L. McKac, and G. S. Bullerjahn. 2006. Optimization of iron-dependent cyanobacterial (Synechococcus, Cyanophyceae) bioreporters to measure iron bioavailability. J. Phycol. 42:324-335.

Hudson, R. J. M., and F. M. M. Morel. 1989. Distinguishing between extra- and intracellular iron in marine phytoplankton. Limnol. Oceanogr. 34:1113-1120.

and - 1990. Iron transport in marine phytoplankton: kinetics of cellular and medium coordination reactions. Limnol. Oceanogr. 35:1002-1020.

- and - 1993. Trace metal transport by marine microorganisms: implications of metal coordination kinetics. Deep-Sea Res. Part I Oceanogr. Res. Pap. 40:129-150.

—, D. T. Covault, and F. M. M. Morel. 1992. Investigations of iron coordination and redox reactions in seawater using iron-59 radiometry and ion-pair solvent extraction of amphiphilic iron complexes. Mar. Chem. 38:209-235.

Leblanc, K., and others. 2005. Fe and Zn effects on the Si cycle and diatom community structure in two contrasting high and low-silicate HNLC areas. Deep-Sea Res. Part I Oceanogr. Res. Pap. 52:1842-1864.

Maldonado, M. T., R. F. Strzepek, S. Sander, and P. W. Boyd. 2005. Acquisition of iron bound to strong organic complexes, with different Fe binding groups and photochemical reactivities, by plankton communities in Fe-limited subantarctic waters. Global Biogeochem. Cycles 19:GB4S23, doi:10.1029/2005GB002481. 
Maranger, R., and J. Pullin. 2003. Elemental complexation by dissolved organic matter in lakes: implications for $\mathrm{Fe}$ speciation and the bioavailability of Fe. In : S. Findlay and R. Sinsabaugh [eds.], Aquatic Ecosystems: Interactivity of Dissolved Organic Matter. New York, Academic Press, p. 185-214.

Morel, F. M. M., J. C. Westhall, J. J. G. Rueter, and J. P. Chaplick. 1975. Description of algal growth media AQUIL and FRAQUIL. Technical Note, R. M. Parsons Laboratory for Water Resources and Hydrodynamics, Massachusetts Institute of Technology, Cambridge, MA.

- and J. G. Hering. 1993. Principles and Applications of Aquatic Chemistry. New York, Wiley Interscience.

NIST (National Institute of Standards and Technology). 2003. Critically selected stability constants of metal complexes database: version 8.0. Standard Reference Data Program, NIST.

Price, N. M., and others. 1988/1989. Preparation and chemistry of the artificial algal culture medium AQUIL. Biol. Oceanogr. 6:443-461.

Saito. M. A., J. W. Moffett, S. W. Chisholm, and J. B. Waterbury. 2002. Cobalt limitation and uptake in Prochlorococcus. Limnol. Oceanogr. 47:1629-1636.

and T. J. Goepfert, 2008. Zinc-cobalt colimitation of Phaeocystis antarctica. Limnol. Oceanogr. 53:266-275.

Sarthou, G., K. R. Timmermans, S. Blain, and P. Treguer. 2005. Growth physiology and fate of diatoms in the ocean: a review. J. Sea Res. 53:25-42.

Schoemann, V., R. Wollast, L. Chou, and C. Lancelot. 2001. Effects of photosynthesis on the accumulation of $\mathrm{Mn}$ and Fe by Phaeocystis colonies. Limnol. Oceanogr. 46:1065-1076.

- S. Becquevort, J. Stefels, V. Rousseau, and C. Lancelot. 2005. Phaeocystis blooms in the global ocean and their controlling mechanisms: a review. J. Sea Res. 53:43-66.

Shaked, Y., A. B. Kustka, and F. M. M. Morel. 2005. A general kinetic model for iron acquisition by eukaryotic phytoplankton. Limnol. Oceanogr. 50:872-882.

Smith, W. O. Jr, and V. A. Asper. 2001. The influence of phytoplankton assemblage composition on biogeochemical characteristics and cycles in the southern Ross Sea, Antarctica. Deep-Sea Res. Part I Oceanogr. Res. Pap. 48:137-161.

Sterner R. W., T. M. Smutka, R. M. L. McKay, Q. Xiaoming, E. T. Brown, and R. M. Sherrell. 2004. Phosphorus and trace metal limitation of algae and bacteria in Lake Superior. Limnol. Oceanogr. 49:495-507.

Sulzberger, B., and H. Laubscher. 1995. Reactivity of various types of iron(III) (hydr)oxides towards light-induced dissolution. Mar. Chem. 50:103-115.

—, D. Suter, C. Siffert, S. Banwart, and W. Stumm. 1989. Dissolution of Fe (III) (hydr) oxides in natural waters: laboratory assessment on the kinetics controlled by surface coordination. Mar. Chem. 28:127-144.
Tang, D., and F. M. M. Morel. 2006. Distinguishing between cellular and Fe-oxide-associated trace elements in phytoplankton. Mar. Chem. 98:18-30.

Tovar-Sanchez, A., S. A. Sanudo-Wilhelmy, M. Garcia-Vargas, R. S. Weaver, L. C. Popels, and D. A. Hutchins. 2003. A trace metal clean reagent to remove surface-bound iron from marine phytoplankton. Mar. Chem. 82:91-99. Published erratum, Mar. Chem. 2004;85:191.

Turner, D. R., and K. A. Hunter. 2001. The biogeochemistry of iron in seawater. IUPAC series on analytical and physical chemistry of environmental systems, Vol. 7. New York, John Wiley and Sons.

Twining, B. S., S. B. Baines, N. S. Fisher, and M. R. Landry. 2004. Cellular iron contents of plankton during the Southern Ocean Iron Experiment (SOFeX). Deep-Sea Res. I 51:1827-1850.

Twiss, M. R., J. C. Auclair, and M. N. Charlton. 2000. An investigation into iron-stimulated phytoplankton productivity in epipelagic Lake Erie during thermal stratification using trace metal clean techniques. Can. J. Fish. Aquat. Sci. 57:8695.

Van Leeuwe, M. A., and J. Stefels. 1998. Effects of Fe and light stress on the biochemical composition of Antarctic Phaeocystis sp. (Prymnesiophyceae). II. Pigment composition. J. Phycol. 34:496-503.

Völker, C., and D. A. Wolf-Gladrow. 1999. Physical limits on iron uptake mediated by siderophores or surface reductases. Mar. Chem. 65:227-244.

Wedepohl, H. K. 1995. The composition of the continental crust. Geochim. Cosmochim. Acta 59:1217-1232.

Wilhelm, S. W. 1995. Ecology of iron-limited cyanobacteria: a review of physiological responses and implications for aquatic systems. Aquat. Microb. Ecol. 9:295-303.

Wilkinson, K. J., and J. Buffle. 2004. Physicochemical kinetics and transport at biointerfaces. In: H. P. van Leeuwen, W. Köster [eds.], IUPAC Series on Analytical and Physical Chemistry of Environmental Systems, Vol. 9. New York, John Wiley \& Sons, p. 445-533.

Worms, I., D. F. Simon, C. S. Hassler, and K. J. Wilkinson. 2006. Bioavailability of trace metals to aquatic microorganisms: importance of chemical, biological and physical processes on biouptake. Biochimie 88:1721-1731.

Wu, J., E. Boyle, W. Sunda, and L.-S. Wen. 2001. Soluble and colloidal iron in the oligotrophic North Atlantic and North Pacific. Science 293:847-849.

Young, E. O., and D. S. Ross. 2001. Phosphate release from seasonally flooded soils: a laboratory microcosm study. J. Environ. Qual. 30:91-101.

Submitted 20 September 2008 Revised 8 April 2009 Accepted 29 May 2009 